\title{
Modified Maturity Offset Prediction Equations: Validation in Independent Longitudinal Samples of Boys and Girls
}

\author{
Sławomir M. Koziel $^{1} \cdot$ Robert M. Malina $^{2,3}{ }_{(\mathbb{D}}$
}

Published online: 12 June 2017

(c) The Author(s) 2017. This article is an open access publication

\begin{abstract}
Background Predicted maturity offset and age at peak height velocity are increasingly used with youth athletes, although validation studies of the equations indicated major limitations. The equations have since been modified and simplified.

Objective The objective of this study was to validate the new maturity offset prediction equations in independent longitudinal samples of boys and girls.

Methods Two new equations for boys with chronological age and sitting height and chronological age and stature as predictors, and one equation for girls with chronological age and stature as predictors were evaluated in serial data from the Wrocław Growth Study, 193 boys (aged 8-18 years) and 198 girls (aged 8-16 years). Observed age at peak height velocity for each youth was estimated with the Preece-Baines Model 1. The original prediction equations were included for comparison. Predicted age at peak height velocity was the difference between chronological age at prediction and maturity offset.
\end{abstract}

Electronic supplementary material The online version of this article (doi:10.1007/s40279-017-0750-y) contains supplementary material, which is available to authorized users.

Robert M. Malina

rmalina@1skyconnect.net

Sławomir M. Kozieł

slawomir.koziel@iitd.pan.wroc.pl

1 Department of Anthropology, Hirszfeld Institute of Immunology and Experimental Therapy, Polish Academy of Sciences, Wrocław, Poland

2 Department of Kinesiology and Health Education, University of Texas, Austin, TX, USA

310735 FM 2668, Bay City, TX 77414, USA
Results Predicted ages at peak height velocity with the new equations approximated observed ages at peak height velocity in average maturing boys near the time of peak height velocity; a corresponding window for average maturing girls was not apparent. Compared with observed age at peak height velocity, predicted ages at peak height velocity with the new and original equations were consistently later in early maturing youth and earlier in late maturing youth of both sexes. Predicted ages at peak height velocity with the new equations had reduced variation compared with the original equations and especially observed ages at peak height velocity. Intra-individual variation in predicted ages at peak height velocity with all equations was considerable.

Conclusion The new equations are useful for average maturing boys close to the time of peak height velocity; there does not appear to be a clear window for average maturing girls. The new and original equations have major limitations with early and late maturing boys and girls. 


\section{Key Points}

Predicted maturity offset and age at peak height velocity (PHV) were dependent upon chronological age and probably size at prediction; predicted offset systematically decreased and age at PHV systematically increased with chronological age at prediction.

Variation in predicted ages at PHV with the new equations was systematically reduced compared with predictions with the original equations and observed ages at PHV.

Predicted age at PHV with the new equations was quite accurate for average maturing boys within \pm 1 year of observed PHV; a corresponding window for average maturing girls was not apparent.

Predicted ages at PHV were systematically later than observed ages at PHV in early maturing boys and girls, and systematically earlier than observed ages at PHV in late maturing boys and girls.

The Bland-Altman regressions indicated a lack of fit between predicted and observed ages at PHV within each chronological age group and within each year before and after PHV; slopes for the new equations were greater than those for the original equations.

Intra-individual variation in predicted ages at PHV with the new and original equations was considerable.

\section{Introduction}

Individual differences in biological maturation are important considerations in youth sport and talent development, and in studies of physical activity [1]. Established indicators of maturity status [skeletal age (SA), secondary sex characteristics] are often perceived as impractical and invasive. As such, there is interest in 'non-invasive' indicators $[1,2]$. Predicted maturity offset, defined as the time before or after peak height velocity (PHV), is one such indicator; chronological age (CA) at prediction minus offset provides an estimate of age at PHV [3].

Both predicted offset and age at PHV are increasingly used in studies of sport, performance and physical activity among youth spanning late childhood through adolescence [1]. The interval of PHV is also central to the long-term athlete development model [4,5], while attention to individual differences in biological maturation is increasingly recommended in the design of conditioning and training programmes for youth [6-8] and in talent development [9].

Although the original sex-specific prediction equations [3] for the prediction of maturity offset are widely used, validation studies indicated several limitations in both sexes [10-12]. The original equations have since been refined, simplified and modified to include fewer predictors and to accommodate the lack of a measurement of sitting height in many studies [13]. Published applications of the new equations are limited to date [14-17].

The purpose of this study is to validate the new maturity offset prediction equations. It specifically compares predicted ages at PHV based on the new equations with observed age at PHV in longitudinal samples of boys and girls used in validations of the original equations [10, 11]. Predictions based on the original equations [3] are included for comparison. Predictions are compared by CA group from late childhood through adolescence and by years before and after observed age at PHV. Comparisons are also made among boys and girls of contrasting maturity status (early, average, late) defined by observed age at PHV.

\section{Methods}

\subsection{Participants}

Data are from the Wrocław Growth Study, which followed Polish boys and girls from 1961 through 1972. The study was approved and funded by the Polish Academy of Sciences. Details of the study have been summarised [10,11]. The analysis is based on serial data for 193 boys aged 8-18 years and 199 girls aged $8-16$ years. The samples represented $45 \%$ of the total number measured in 1961 and did not differ in height at 8 years from those who dropped out. Based on paternal education and occupation, families of the children were characteristic of the Wroclaw population. Polish law at the time did not require written consent of parents for children to participate in growth studies. Parental presence at annual examinations was accepted as implicit informed consent. However, children were free to withdraw at any time.

\subsection{Anthropometry}

Body mass, stature and sitting height were measured annually by trained and experienced staff in the laboratory of the Institute of Anthropology; the protocols and estimated measurement variability have been reported $[10,11]$. Leg length was estimated as stature minus sitting height. 


\subsection{Age at Peak Height Velocity}

Serial heights for each individual were fitted with the Preece-Baines Model 1 to estimate age at PHV [10, 11]. Descriptive statistics were as follows: girls, $11.89 \pm 1.00$ years, range 9.03-14.82 years; boys, $14.06 \pm 1.11$ years, range $11.45-7.34$ years.

\subsection{Predicted Maturity Offset}

Two new sex-specific equations (labelled Moore-1) were recommended [13]:

Girls:

Maturity offset $($ years $)=-7.709133+(0.0042232$

$$
\times(\text { age } \times \text { stature }),
$$

Boys:

Maturity offset $($ years $)=-8.128741+(0.0070346$ $\times($ age $\times$ sitting height $))$.

An alternative equation (labelled Moore-2) was also provided for boys:

Maturity offset $($ years $)=-7.999994+(0.0036124$

$$
\times(\text { age } \times \text { stature })) \text {. }
$$

Standard errors of the equations were 0.528 year in girls and 0.514 and 0.542 year in boys.

The new equations [13] were based on Canadian youth in the Pediatric Bone Mineral Accrual Study (PBMAS, 1991-7, 79 boys, 72 girls), and cross-validated on Canadian youth from the Healthy Bones Study III (1999-2012, 42 boys, 39 girls) and English youth in the Harpenden Growth Study (1948-71, 38 boys, 32 girls). All youth were of European ancestry. Ages at PHV were estimated with cubic splines: PBMAS, boys $13.4 \pm 0.7$ years (11.1-15.6 years), girls $11.9 \pm 0.7$ years (10.3-13.6 years); Healthy Bones Study III, boys $13.5 \pm 1.1$ years (10.9-15.9 years), girls $11.6 \pm 0.7$ years (10.5-13.4 years); and Harpenden Growth Study, boys $14.0 \pm 1.0$ years (11.3-16.2 years), girls $12.1 \pm 1.0$ years $(9.8-14.2$ years $)$.

Predictions with the original sex-specific equations (labelled Mirwald) [3] were included for comparison:

Girls: Maturity offset (years) $=-9.376+(0.0001882$

$\times($ leg length $\times$ sitting height $))+(0.0022 \times($ age

$\times$ leg length $))+(0.005841 \times($ age $\times$ sitting height $))$

$-(0.002658 \times($ age $\times$ mass $))+(0.07693$

$\times($ mass by stature ratio $\times 100))$;

and
Boys: $\quad$ Maturity offset (years) $=-9.236+((0.0002708$

$\times$ (leg length $\times$ sitting height $)$ )

$+(-0.001663 \times($ age $\times$ leg length $))+(0.007216$

$\times($ age $\times$ sitting height $))$

$+(0.02292 \times($ mass by stature ratio $\times 100))$.

The equations were based on three studies: PBMAS, the Saskatchewan Growth and Development Study (1964-73, 71 boys, 40 girls) and the Leuven Longitudinal Twin Study (1985-99, 50 boys, 48 girls). All youth were of European ancestry. Standard errors of the equations were 0.569 year in girls and 0.592 year in boys [3].

Predicted age at PHV (years) was the difference between $\mathrm{CA}$ and maturity offset with each equation. Although predicted maturity offset and age at PHV are reported, the analyses focused on predicted age at PHV and the difference of predicted minus observed ages at PHV.

\subsection{Analyses}

Descriptive statistics (means, standard deviations) were calculated by CA group for actual and predicted maturity offset, predicted age at PHV and the difference of predicted minus observed age at PHV with each equation. The whole year was the midpoint of the range defining CA groups, i.e. $8.0=7.50-8.49$ years. Corresponding statistics (except for actual offset) were calculated relative to years before/after observed PHV: $-3=-2.51$ to $-3.50,-2=-1.51$ to $-2.50,-1=-0.51$ to $-1.50,0=-0.50$ to +0.49 , $+1=+0.50$ to $+1.49,+2=+1.50$ to +2.49 and $+3=+2.50$ to +3.49 .

Each individual was also classified as early, average or late maturing using sex-specific mean observed ages at PHV \pm 1.0 year for the total samples of boys and girls, respectively. The band of 1 year approximated standard deviations for ages at PHV in longitudinal studies [18] and for SA by CA group from 10 to 17 years [19]. Boys and girls with an observed age at PHV within \pm 1.0 year of the sex-specific mean were thus classified average maturing or on time, i.e. ages at PHV between 13.1 and 15.1 years in boys and between 10.9 and 12.9 years in girls. Boys and girls with an observed age at PHV $<13.1$ and $<10.9$ years, respectively, were classified as early maturing, while boys and girls with an observed age at PHV $>15.1$ and $>12.9$ years, respectively, were classified as late maturing. Sample sizes and means and standard deviations for age at PHV in each maturity group were as follows: boysearly, $n=36, \quad 12.57 \pm 0.41$ years; average, $n=117$, $13.97 \pm 0.52$ years; late, $n=40,15.69 \pm 0.56$ years; and 
girls-early, $n=28,10.19 \pm 0.48$ years; average, $n=140$, $11.91 \pm 0.52$ years; late, $n=30, \quad 13.38 \pm 0.41$ years. Descriptive statistics for each group were calculated by CA and relative to $\mathrm{PHV}$.

Sex-specific analyses were done by CA group and relative to PHV for each equation in the total sample and by maturity groups. Differences of predicted minus observed ages at PHV were tested separately for each equation with two-way analyses of variance; CA groups or years before and after PHV and method (predicted vs. observed) were independent variables. Pairwise comparisons were evaluated with Tukey's honest significant difference test.

Sex-specific Bland-Altman [20] plots and regressions of the difference of predicted minus observed ages at PHV ( $y$ axis) and the mean of predicted and observed ages at PHV ( $x$-axis) were performed for each equation by CA group and year before/after PHV. The slopes provided an estimate of bias and limit of agreement between predicted and observed ages at PHV.

Percentages of predicted ages at PHV within \pm 0.5 year of observed age at PHV for boys and girls in each maturity group were also calculated by CA group and year before/ after PHV. The \pm 0.5 year band approximated the standard errors of the prediction equations. All calculations were done with Statistica 12.0 (Statistica, Tulsa, Oklahoma, USA) [21]. Predicted ages at PHV at each observation were also plotted relative to observed age at PHV for each individual to highlight intra-individual variation.

\section{Results}

\subsection{Total Samples}

Descriptive statistics and significance of differences of predicted minus observed ages at $\mathrm{PHV}$ by CA group are summarised in Tables 1 and 2. Several youth had two observations that fell within an age class; one observation was removed. Several also missed an examination in late adolescence. Predicted maturity offset with each equation is, on average, negative and greatest at 8 years of age and decreases linearly with $\mathrm{CA}$; mean predicted offset approximates zero at 12 years of age in girls and 14 years of age in boys.

Mean predicted ages at PHV increase with CA, but standard deviations are reduced, more so for the new equations. Ranges of predicted ages are also reduced: boys - Moore-1: 0.96-2.52 years, Moore-2: 0.97-2.25, Mirwald: 1.43-3.30 years; and girls - Moore-1: 0.98-2.04 years, Mirwald: 1.57-2.49 years. As noted in Sect. 2, standard deviations and especially ranges for observed ages at PHV are larger.
Relative to PHV, mean predicted ages at PHV with the Moore equations in boys increase from -3 years to $\mathrm{PHV}$ and are then relatively stable, while predictions with Mirwald increase from -3 to -1 year of PHV and are then relatively stable (Table 3 ). Mean differences are negative in boys at -3 and -2 years for the new equations (predicted earlier than observed) but approximate zero at -1 year through +2 years of PHV. The mean difference with Mirwald is negative at -3 years, approaches zero at -2 years, and is then positive and stable from -1 year through +2 years of PHV. Among girls, in contrast, predicted ages at PHV with the new and original equations are similar to observed age at PHV at -3 years and then increase (Table 4). Standard deviations for predicted ages at PHV with the new equations are consistently less than with the original equations in both sexes.

Slopes of the sex-specific Bland-Altman regressions for each prediction equation are negative and significant, and indicate consistent bias by CA group [Table 1 of the Electronic Supplementary Material (ESM)] and by years relative to PHV (Table 2 of the ESM). The slopes are greater for the new equations at all ages in boys and from 8 to 14 years in girls, and from -3 through +3 years of PHV in both sexes.

\subsection{Contrasting Maturity Groups}

Mean differences of predicted minus observed ages at PHV for each equation in youth of contrasting maturity status are shown by CA and relative to PHV in Fig. 1 (boys) and Fig. 2 (girls). Corresponding descriptive statistics and significance of differences are summarised in Tables 3 and 4 of the ESM.

Mean differences of predicted minus observed ages at PHV with the new and original equations are positive and increase with CA in early maturing boys (except at 8 years) and girls, and are negative and increase with $\mathrm{CA}$ in late maturing boys and girls (except at 16 years). Predicted ages at PHV are later than observed age at PHV in early maturing and earlier than observed age at PHV in late maturing boys and girls. The mean differences are similar between the Moore equations and vary only slightly from Mirwald in early and late maturing boys (Fig. 1a). Corresponding differences between equations are similar in early maturing girls, but are larger for Moore than Mirwald in late maturing girls (Fig. 2a).

Among average maturing boys, mean differences of predicted minus observed ages at PHV are negligible between Moore-1 and Moore-2. Predicted ages are less than observed age at PHV from 8 to 12 years, about equivalent at 13-15 years, and greater from 16 to 18 years. For Mirwald, predicted ages are less than observed age at PHV from 8 to 11 years, about equal at 12 years and 


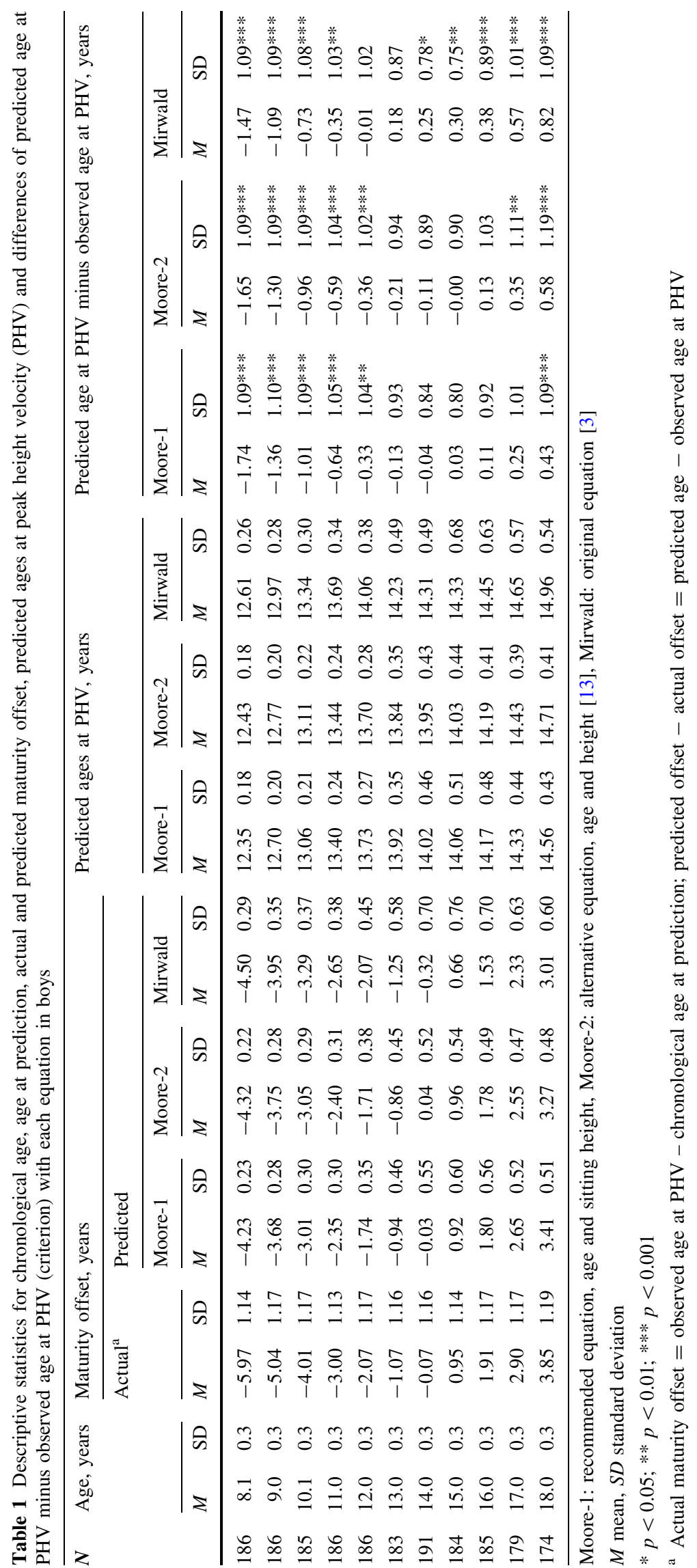


Table 2 Descriptive statistics for chronological age, actual maturity offset, predicted maturity offset and ages at peak height velocity (PHV), and the differences of predicted age at PHV minus observed age at PHV (criterion) with each equation in girls

\begin{tabular}{|c|c|c|c|c|c|c|c|c|c|c|c|c|c|c|c|c|}
\hline \multirow[t]{4}{*}{$N$} & \multirow{3}{*}{\multicolumn{2}{|c|}{$\begin{array}{l}\text { Age, } \\
\text { years }\end{array}$}} & \multicolumn{6}{|c|}{ Maturity offset, years } & \multirow{2}{*}{\multicolumn{4}{|c|}{ Predicted age at PHV, years }} & \multirow{2}{*}{\multicolumn{4}{|c|}{$\begin{array}{l}\text { Predicted age at PHV minus observed } \\
\text { age at PHV, years }\end{array}$}} \\
\hline & & & \multirow{2}{*}{\multicolumn{2}{|c|}{ Actual $^{\mathrm{a}}$}} & \multicolumn{4}{|c|}{ Predicted } & & & & & & & & \\
\hline & & & & & \multicolumn{2}{|c|}{ Moore-1 } & \multicolumn{2}{|c|}{ Mirwald } & \multicolumn{2}{|c|}{ Moore-1 } & \multicolumn{2}{|c|}{ Mirwald } & \multicolumn{2}{|l|}{ Moore-1 } & \multicolumn{2}{|l|}{ Mirwald } \\
\hline & $M$ & SD & $M$ & SD & $M$ & SD & $M$ & SD & $M$ & SD & $M$ & SD & $M$ & SD & $M$ & SD \\
\hline 196 & 8.0 & 0.3 & -3.85 & 1.04 & -3.52 & 0.26 & -3.56 & 0.35 & .57 & 0.19 & 11.60 & 0.29 & $-0.33 * *$ & 0.94 & $-0.29 *$ & 0.91 \\
\hline 175 & 9.0 & 0.3 & -2.90 & 1.05 & -2.84 & 0.31 & -2.88 & 0.39 & 11.82 & 0.22 & 11.85 & 0.32 & -0.06 & 0.93 & -0.03 & 0.90 \\
\hline 188 & 10.0 & 0.3 & -1.88 & 1.05 & -2.07 & 0.36 & -2.13 & 0.45 & 12.07 & 0.27 & 12.13 & 0.38 & 0.19 & 0.89 & 0.24 & 0.84 \\
\hline 185 & 11.0 & 0.3 & -0.87 & 1.03 & -1.22 & 0.39 & -1.28 & 0.48 & 12.24 & 0.32 & 12.29 & 0.43 & $0.35 * * *$ & 0.85 & $0.41 * * *$ & 0.80 \\
\hline 181 & 12.0 & 0.3 & 0.25 & 1.00 & -0.28 & 0.45 & -0.36 & 0.54 & 12.31 & 0.37 & 12.40 & 0.48 & $0.43 * * *$ & 0.77 & $0.50 * * *$ & 0.71 \\
\hline 190 & 13.0 & 0.3 & 1.09 & 1.03 & 0.63 & 0.47 & 0.50 & 0.53 & 12.38 & 0.38 & 12.51 & 0.46 & $0.46^{* * * *}$ & 0.86 & $0.59 * * *$ & 0.79 \\
\hline 196 & 14.0 & 0.3 & 2.12 & 1.02 & 1.51 & 0.45 & 1.32 & 0.47 & 12.50 & 0.37 & 12.68 & 0.41 & $0.62 * * *$ & 0.95 & $0.79 * * *$ & 0.88 \\
\hline 186 & 15.0 & 0.3 & 3.12 & 1.05 & 2.31 & 0.45 & 2.04 & 0.44 & 12.71 & 0.38 & 12.97 & 0.40 & $0.81 * * *$ & 1.03 & $1.08 * * *$ & 0.98 \\
\hline 173 & 16.0 & 0.3 & 4.12 & 1.03 & 3.03 & 0.44 & 2.64 & 0.41 & 12.98 & 0.41 & 13.35 & 0.40 & $1.08 * * *$ & 1.05 & $1.46^{* * *}$ & 1.01 \\
\hline
\end{tabular}

Moore-1: recommended equation with age and height [7], Mirwald: original equation [3]

$M$ mean, $S D$ standard deviation

$* p<0.05 ; * * p<0.01 ; * * * p<0.001$

${ }^{a}$ Actual maturity offset $=$ observed age at PHV - chronological age at prediction; predicted offset - actual offset $=$ predicted age - observed age at PHV

greater from 13 to 18 years (Fig. 1a). Among average maturing girls, predicted ages at PHV are slightly earlier at 8 years, approximate observed age at PHV at 9 years and are later at 10-16 years (Fig. 2a). Differences of predicted minus observed ages at PHV between Moore-1 and Mirwald are small from 8 to 12 years but increase with age.

Relative to years before/after PHV, mean differences of predicted minus observed ages at PHV are similar for the Moore equations and less than those for Mirwald in early maturing boys; the differences are positive (predicted later than observed) and increase from -3 to +3 years of PHV (Fig. 1b). The corresponding differences are similar for Moore-1 and Mirwald among early maturing girls, and are positive and increase from -3 to +3 years (Fig. 2b).

Differences of predicted minus observed ages at PHV are negative (predicted earlier than observed) from -3 to +3 years of PHV in late maturing boys; predicted ages at PHV with the Moore equations are markedly earlier than observed age at PHV. Corresponding differences among late maturing girls are also negative; predicted ages at PHV are earlier than observed ages, more so with Moore-1 than Mirwald, except at +3 years.

Among average maturing boys, differences of predicted minus observed ages at PHV are negligible between Moore equations; the differences are negative at -3 and -2 years, approximate zero from -1 year to +2 years and increase at +3 years (Fig. 1b). Corresponding differences with Mirwald are negative at -3 years, near zero at -2 years and then positive. In contrast, mean differences of predicted minus observed ages at PHV in average maturing girls approximate zero at -3 years with both equations (Fig. 2b), and are then positive and increase through +3 years (predicted later than observed).

Percentages of predicted ages at PHV within \pm 0.5 year of observed age at PHV in youth of contrasting maturity status are summarised by $\mathrm{CA}$ and relative to PHV in Tables 5 and 6 , respectively. Predictions within \pm 0.5 year of observed age at PHV are highest at 9 years of age and at -3 years of PHV in early maturing boys and then decline by $\mathrm{CA}$ and relative to PHV; few predictions are within \pm 0.5 year of observed PHV from -1 through +3 years of PHV. By CA and relative to PHV, only one prediction (with Mirwald) is within \pm 0.5 year of observed PHV in early maturing girls. The trends are generally similar for late maturing boys, especially with the new equations, while percentages of predictions within \pm 0.5 year of observed age at PHV overlap for the new and original equations among late maturing girls.

Among average maturing boys, percentages of predicted ages at PHV within \pm 0.5 year of observed age at PHV with Moore-1 and Moore-2 increase from 8 to 14 years and then decline, while percentages with Mirwald are rather stable $(\sim 60 \%)$ from 11 to 16 years (Table 5$)$. Among average maturing girls, corresponding percentages with Moore- 1 and Mirwald are highest at 10 years $(\sim 65 \%)$ and then decline. Predictions within \pm 0.5 year of observed 


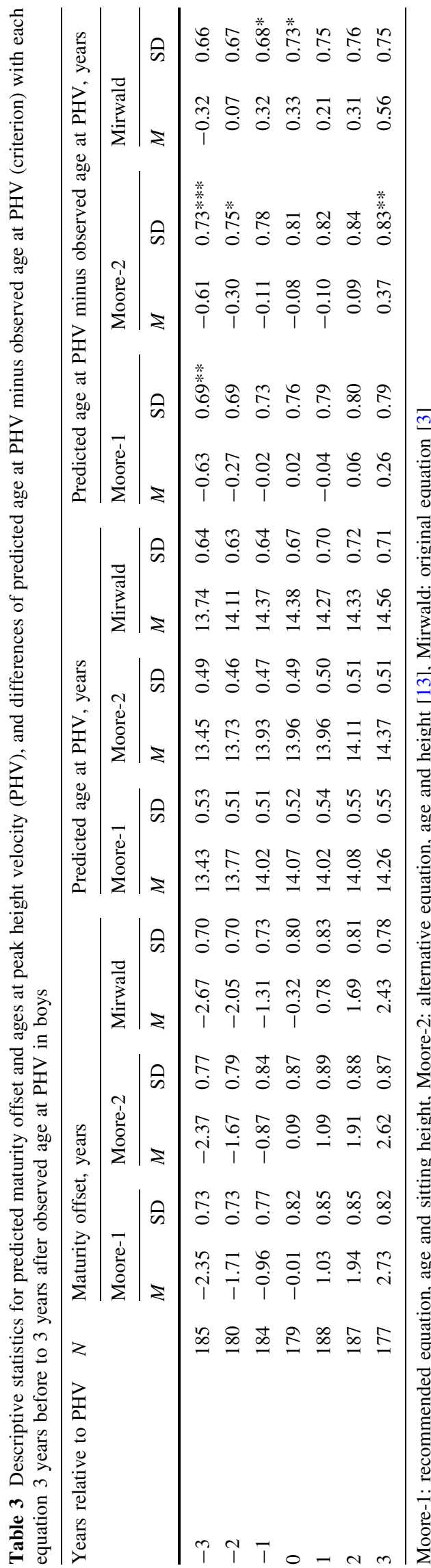

age at PHV are rather stable from -2 to +2 years of PHV with the new equations $(\sim 71-79 \%)$ in average maturing boys; percentages with Mirwald are highest at -2 years but then decline (Table 6). In contrast, percentages are highest at -3 years of PHV with both equations (81\%) and then systematically decline in average maturing girls.

\subsection{Intra-Individual Variation}

Predicted ages at PHV (y-axis) for individual youth with each equation are illustrated relative to observed ages at PHV ( $x$-axis) in Fig. 3 (boys) and Fig. 4 (girls). Intra-individual variation in predicted ages at PHV is considerable and ranges of predicted ages are reduced with the new equations. Relatively few predicted ages approximate observed ages at PHV in early and late maturing boys and girls.

\section{Discussion}

Results of the validation analysis of the new maturity offset prediction equations [13] were consistent with those for the original equations in Polish [10,11] and American [12] youth. The combined results of the four analyses indicated several trends:

First, predicted maturity offset decreased and age at PHV increased, on average, with CA at prediction throughout the range considered. This likely reflected the dependence of the predictions upon CA and probably body size at prediction.

Second, variation in predicted ages at PHV within CA groups was reduced compared with variation in observed ages at PHV. Moreover, variation with the new equations was reduced compared with that for the original equations.

Third, predictions of age at PHV were influenced by observed or actual age at PHV, especially among early and late maturing youth. Predicted ages at PHV with the new and original equations were consistently later than observed age at PHV among early maturing, and earlier than observed age at PHV in late maturing youth of both sexes.

Fourth, predicted ages at PHV with the new equations were quite accurate for average maturing boys within \pm 1 year of observed PHV. A corresponding window for average maturing girls was not evident.

Fifth, intra-individual variation in predicted ages at PHV with the modified and original equations was considerable. Relatively few predicted ages at PHV in early and late maturing boys and girls approximated observed age at PHV.

Sixth, slopes of the Bland-Altman regressions for all predictions were negative by $\mathrm{CA}$ and year from -3 to +3 years of 
Table 4 Descriptive statistics for predicted maturity offset and ages at peak height velocity (PHV), and differences of predicted age at PHV minus observed age at PHV (criterion) with each equations 3 years before to 3 years after observed age at PHV in girls

\begin{tabular}{|c|c|c|c|c|c|c|c|c|c|c|c|c|c|}
\hline \multirow[t]{3}{*}{$\begin{array}{l}\text { Years relative } \\
\text { to } \mathrm{PHV}\end{array}$} & \multirow[t]{3}{*}{$N$} & \multicolumn{4}{|c|}{ Maturity offset, years } & \multicolumn{4}{|c|}{ Predicted age at PHV, years } & \multicolumn{4}{|c|}{$\begin{array}{l}\text { Predicted age at PHV minus observed } \\
\text { age at PHV, years }\end{array}$} \\
\hline & & \multicolumn{2}{|c|}{ Moore-1 } & \multicolumn{2}{|c|}{ Mirwald } & \multicolumn{2}{|c|}{ Moore-1 } & \multicolumn{2}{|c|}{ Mirwald } & \multicolumn{2}{|l|}{ Moore-1 } & \multicolumn{2}{|l|}{ Mirwald } \\
\hline & & $M$ & SD & $M$ & SD & $M$ & $\mathrm{SD}$ & $M$ & SD & $M$ & SD & $M$ & SD \\
\hline-3 & 176 & -2.78 & 0.58 & -2.84 & 0.57 & 11.89 & 0.38 & 11.95 & 0.47 & -0.11 & 0.56 & -0.17 & 0.57 \\
\hline-2 & 181 & -2.13 & 0.70 & -2.20 & 0.67 & 12.07 & 0.41 & 12.14 & 0.52 & 0.17 & 0.65 & 0.23 & 0.61 \\
\hline-1 & 187 & -1.32 & 0.77 & -1.39 & 0.71 & 12.25 & 0.42 & 12.33 & 0.55 & $0.37 *$ & 0.72 & $0.44 *$ & 0.65 \\
\hline 0 & 188 & -0.37 & 0.80 & -0.46 & 0.72 & 12.31 & 0.42 & 12.41 & 0.56 & $0.41 *$ & 0.74 & $0.50^{*}$ & 0.65 \\
\hline 1 & 187 & 0.61 & 0.84 & 0.48 & 0.73 & 12.33 & 0.42 & 12.45 & 0.54 & $0.42 *$ & 0.78 & $0.54 *$ & 0.67 \\
\hline 2 & 196 & 1.49 & 0.81 & 1.33 & 0.69 & 12.45 & 0.45 & 12.62 & 0.57 & $0.54 *$ & 0.77 & $0.71 *$ & 0.65 \\
\hline 3 & 181 & 2.22 & 0.81 & 1.96 & 0.67 & 12.65 & 0.46 & 12.88 & 0.56 & $0.82 *$ & 0.78 & $1.07 *$ & 0.65 \\
\hline
\end{tabular}

Moore-1: recommended equation, age and height [13], Mirwald: original equation [3]

$M$ mean, $S D$ standard deviation

$* p<0.001$

PHV in both sexes, and indicated a bias between predicted and observed ages at PHV. Slopes were greater for the new compared with the original equations.

Prior to discussing implications of the present validation study, the labels maturation, maturity status and maturity timing require clarification as they are often treated as synonymous. Maturation is a process, specifically, of progress towards the biologically mature state, which varies among bodily systems. Maturity status refers to the level or state of maturation at the time of observation. Maturity timing refers to the age at which specific maturational events occur [2]. Age at PHV is an indicator of maturity timing - the estimated age at maximal velocity of growth in height during the adolescent spurt. Age at PHV is often discussed relative to SA and stage of puberty (secondary sex characteristics), which are indicators of maturity status. Though related, maturity timing and status are not equivalent, and variation in maturity status at the time of PHV is considerable. In the Wroclaw Growth Study, for example, $\mathrm{SA}$ at the time of PHV ranged from 9.6 to 14.2 years in girls and from $\sim 12.5$ to 15.5 years in boys [22, 23]. In the Zurich longitudinal study, four of the five stages of pubic hair and all five stages of breast development in girls, and all stages of pubic hair and four of the five stages of genital development in boys were evident at the time of PHV [24, 25].

Results of the validation analyses have implications for those working with youth athletes. Identification of the interval of PHV is central in the late specialisation component of the long-term athlete development model [4, 5], while prediction of maturity offset has been discussed in the context of individualising training relative to the timing of the growth spurt [6-8]. However, potential misclassifications and implications of misclassification for individual youth are not considered.

The potential utility of predicted maturity offset as a categorical indicator of maturity status, specifically preand post-PHV, was emphasised in the initial descriptions of the equations [3, 13]. Given results of the present (Figs. 1, 2 ; Tables 5, 6) and earlier validation analyses [10-12], this is likely useful with average maturing boys in single-year CA groups close to the time of PHV, age $\sim 13-15$ years. Unfortunately, the maturity status of youth is not ordinarily known when the equations are applied. A corresponding window for average maturing girls is not apparent, while predictions in early and late maturing youth of both sexes have limited utility for classification purposes.

Classifications of youth as pre- and post-PHV may have merit within a narrow $\mathrm{CA}$ range, but $\mathrm{CA}$ and body size are potential confounders. Among soccer players aged 9.2-10.4 years classified into CA quartiles, maturity offset decreased while height and predicted age at PHV increased from the youngest to oldest quartiles [26]. The influences of CA and size on maturity classifications are more marked in youth spanning several years across adolescence. Among male soccer players aged 11-17 years [27] and 10-18 years [28], sport academy participants aged 11-15 years [29] and school boys aged 11-15 years [30], $\mathrm{CA}$, height and weight increased, on average, from pre- to mid- to post-PHV groups, or by years before or after predicted PHV. The approach was similar to grouping boys by stage of pubic hair or genital development independent of CA [31]. It is likely that 11- and 14-year-old boys classified as pre-PHV or 11- and 15-year-old boys classified as mid-PHV differed in height, weight and perhaps performance. 

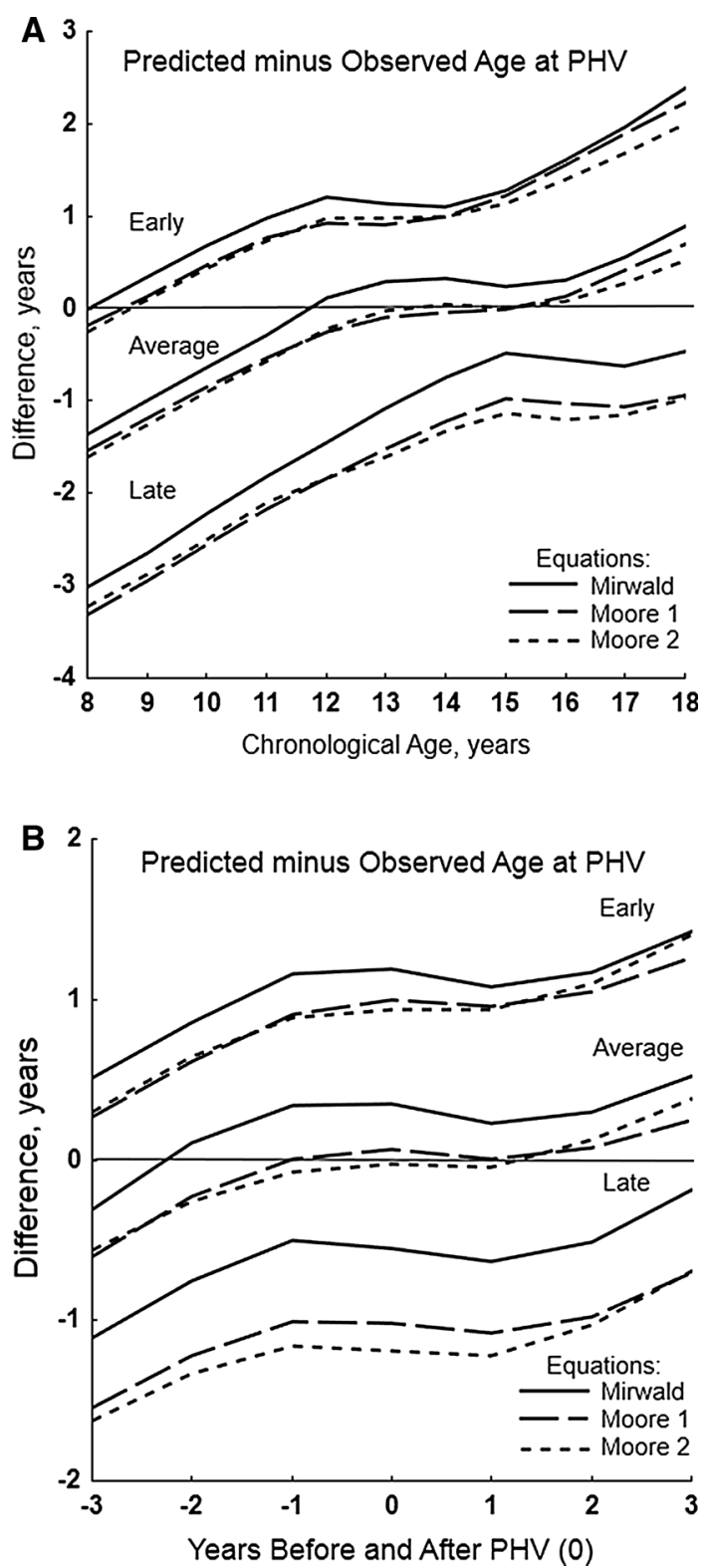

Fig. 1 Means of predicted age at peak height velocity (PHV) minus observed age at PHV with the new (Moore-1, Moore-2) and original (Mirwald) equations in early, average and late maturing boys by age group (a) and years before and after PHV (b); standard errors of the means ranged from 0.03 to 0.12 year

As noted, grouping youth by maturity status is central to many talent development programmes, but reduced variation in predicted ages at PHV (Tables 1,2) limits its utility. For example, youth soccer players aged 11-15 years were classified as early, average and late maturing on the basis of SA and predicted age at PHV. Maturity status was classified by the differences of SA minus CA, and of predicted age at PHV and the average age at PHV of the samples used to develop the original equation [32]. Concordance of maturity classifications (kappa coefficients) based on SA and predicted age of PHV was relatively poor
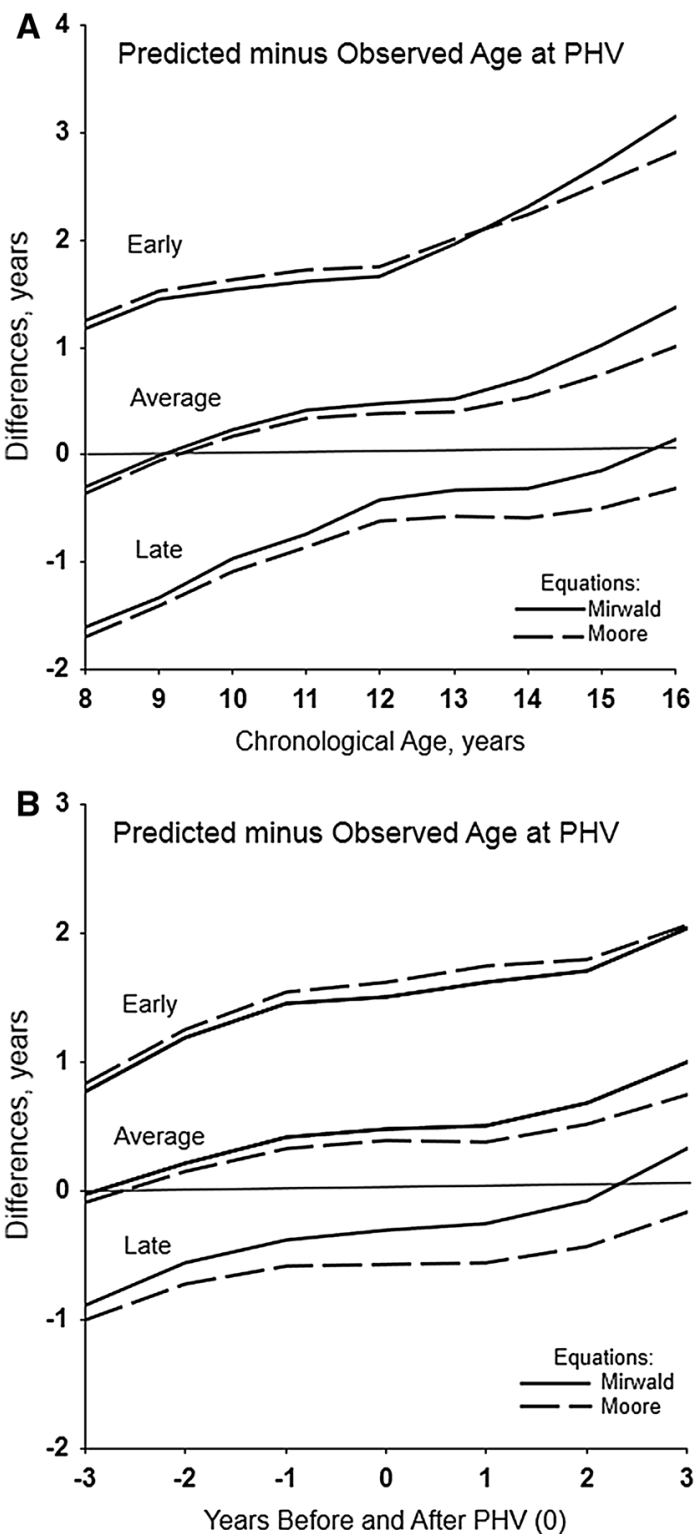

Fig. 2 Means of predicted age at peak height velocity (PHV) minus observed age at PHV with the new (Moore-1) and original (Mirwald) equations in early, average and late maturing girls by age group (a) and years before and after PHV (b); standard errors of the means ranged from 0.04 to 0.12 year

in two age groups of players. Among 87 players aged 11.0-12.9 years, $84(97 \%)$ were classified as average by predicted age at PHV compared with $45(52 \%)$ by SA. Among 93 players aged 13.3-15.3 years, 77 (83\%) were classified as average by predicted age at PHV compared with $55(59 \%)$ by SA [32]. The high percentages of average maturing players reflected the reduced range of variation in predicted ages at PHV.

Predicted offset and/or age at PHV does not effectively discriminate between early and late maturing boys, i.e. it over- and under-estimates age at PHV in early and late 
Table 5 Percentages of predicted ages at peak height velocity (PHV) within \pm 0.5 year of observed age at PHV with the new: Moore-1 (M-1), Moore-2 (M-2) and original: Mirwald (M) equations by age at prediction in boys and girls of contrasting maturity status

\begin{tabular}{|c|c|c|c|c|c|c|c|c|c|c|c|c|c|c|c|}
\hline \multirow{3}{*}{$\begin{array}{l}\text { Age } \\
\text { group }\end{array}$} & \multicolumn{9}{|l|}{ Boys } & \multicolumn{6}{|l|}{ Girls } \\
\hline & \multicolumn{3}{|c|}{$\begin{array}{l}\text { Early } \\
(n=32-36)\end{array}$} & \multicolumn{3}{|c|}{$\begin{array}{l}\text { Average } \\
(n=106-115)\end{array}$} & \multicolumn{3}{|c|}{$\begin{array}{l}\text { Late } \\
(n=37-40)\end{array}$} & \multicolumn{2}{|c|}{$\begin{array}{l}\text { Early } \\
(n=23-28)\end{array}$} & \multicolumn{2}{|c|}{$\begin{array}{l}\text { Average } \\
(n=123-140)\end{array}$} & \multicolumn{2}{|c|}{$\begin{array}{l}\text { Late } \\
(n=25-30)\end{array}$} \\
\hline & M-1 & M-2 & $\mathrm{M}$ & M-1 & M-2 & $\mathrm{M}$ & M-1 & M-2 & M & M-1 & $\mathrm{M}$ & M-1 & $\mathrm{M}$ & M-1 & M \\
\hline 8 & 66 & 75 & 72 & 0 & 1 & 3 & 0 & 0 & 0 & 0 & 4 & 54 & 56 & 0 & 0 \\
\hline 9 & 79 & 79 & 71 & 7 & 12 & 19 & 0 & 0 & 0 & 0 & 0 & 58 & 64 & 0 & 0 \\
\hline 10 & 66 & 66 & 37 & 28 & 31 & 43 & 0 & 0 & 0 & 0 & 0 & 66 & 65 & 3 & 10 \\
\hline 11 & 31 & 25 & 11 & 46 & 50 & 60 & 0 & 0 & 0 & 0 & 0 & 58 & 55 & 14 & 32 \\
\hline 12 & 3 & 11 & 3 & 66 & 63 & 63 & 0 & 0 & 0 & 0 & 0 & 59 & 51 & 46 & 65 \\
\hline 13 & 0 & 9 & 0 & 71 & 71 & 63 & 0 & 0 & 16 & 0 & 0 & 57 & 47 & 53 & 77 \\
\hline 14 & 0 & 8 & 3 & 78 & 74 & 62 & 5 & 3 & 40 & 0 & 0 & 46 & 34 & 52 & 76 \\
\hline 15 & 0 & 0 & 0 & 73 & 68 & 62 & 11 & 11 & 51 & 0 & 0 & 37 & 20 & 67 & 79 \\
\hline 16 & 0 & 0 & 0 & 63 & 62 & 60 & 13 & 8 & 55 & 0 & 0 & 24 & 6 & 65 & 60 \\
\hline 17 & 0 & 0 & 0 & 56 & 45 & 45 & 14 & 14 & 49 & & & & & & \\
\hline 18 & 0 & 0 & 0 & 45 & 34 & 30 & 23 & 26 & 56 & & & & & & \\
\hline
\end{tabular}

M-1: boys—recommended equation, age and sitting height, girls—recommended equation, age and height; M-2: boys-alternative equation, age and height [13]; M: original equation [3]

Table 6 Percentages of predicted ages at peak height velocity (PHV) within \pm 0.50 year of observed age at PHV with the new: Moore-1 (M-1), Moore-2 (M-2) and original: Mirwald (M) equations by years before and after PHV in boys and girls of contrasting maturity status

\begin{tabular}{|c|c|c|c|c|c|c|c|c|c|c|c|c|c|c|c|}
\hline \multirow{3}{*}{$\begin{array}{l}\text { Years relative } \\
\text { to } \mathrm{PHV}\end{array}$} & \multicolumn{9}{|c|}{ Boys } & \multicolumn{6}{|c|}{ Girls } \\
\hline & \multicolumn{3}{|c|}{$\begin{array}{l}\text { Early } \\
(n=34-37)\end{array}$} & \multicolumn{3}{|c|}{$\begin{array}{l}\text { Average } \\
(n=109-116)\end{array}$} & \multicolumn{3}{|c|}{$\begin{array}{l}\text { Late } \\
(n=33-38)\end{array}$} & \multicolumn{2}{|c|}{$\begin{array}{l}\text { Early } \\
(n=13-27)\end{array}$} & \multicolumn{2}{|c|}{$\begin{array}{l}\text { Average } \\
(n=129-140)\end{array}$} & \multicolumn{2}{|c|}{$\begin{array}{l}\text { Late } \\
(n=20-30)\end{array}$} \\
\hline & M-1 & M-2 & $\mathrm{M}$ & M-1 & M-2 & $\mathrm{M}$ & M-1 & M-2 & $\mathrm{M}$ & M-1 & $\mathrm{M}$ & M-1 & M & M-1 & $\mathrm{M}$ \\
\hline-3 & 80 & 80 & 51 & 43 & 50 & 71 & 0 & 0 & 11 & 0 & 0 & 81 & 81 & 3 & 14 \\
\hline-2 & 43 & 40 & 14 & 76 & 71 & 75 & 3 & 0 & 24 & 0 & 4 & 72 & 71 & 22 & 41 \\
\hline-1 & 3 & 8 & 3 & 79 & 77 & 66 & 11 & 11 & 50 & 0 & 0 & 62 & 58 & 52 & 69 \\
\hline PHV & 0 & 6 & 0 & 76 & 75 & 58 & 11 & 8 & 58 & 0 & 0 & 59 & 49 & 55 & 76 \\
\hline+1 & 0 & 9 & 3 & 72 & 73 & 66 & 13 & 8 & 45 & 0 & 0 & 57 & 47 & 53 & 79 \\
\hline+2 & 0 & 3 & 0 & 72 & 66 & 59 & 19 & 22 & 54 & 0 & 0 & 49 & 36 & 67 & 83 \\
\hline+3 & 0 & 0 & 0 & 60 & 49 & 47 & 36 & 36 & 58 & 0 & 0 & 38 & 13 & 77 & 45 \\
\hline
\end{tabular}

M-1: boys—recommended equation, age and sitting height, girls—recommended equation, age and height; M-2: boys-alternative equation, age and height [13]; M: original equation [3]

maturing boys, respectively (Fig. 1), with the result that players are essentially regressed to the mean age of PHV. The preceding highlights limitations of using predicted ages at PHV (maturity timing) to classify youth athletes into maturity status categories, currently labelled biobanding [9]. The offset method has been used to bio-band soccer players for competition [33], but noting the limitations of predicted offset, bio-banded tournaments organised by the English Premier League have used, with some success, an alternative non-invasive predictor of maturity status-percentage of predicted adult height attained at the time of observation [9]. Specifics of the method [2] and its application are beyond the scope of this discussion [9].

Variation in the skeletal maturity status of youth male athletes in several sports has relevance for the preceding discussion. Allowing for variation among methods of SA assessment, reasonably similar proportions of late, average and early maturing boys were represented in sport-specific samples of athletes at 11-12 years of age. With increasing $\mathrm{CA}$, proportions of late maturing players declined while proportions of average and early maturing players increased. Moreover, several 14-year-old male athletes 

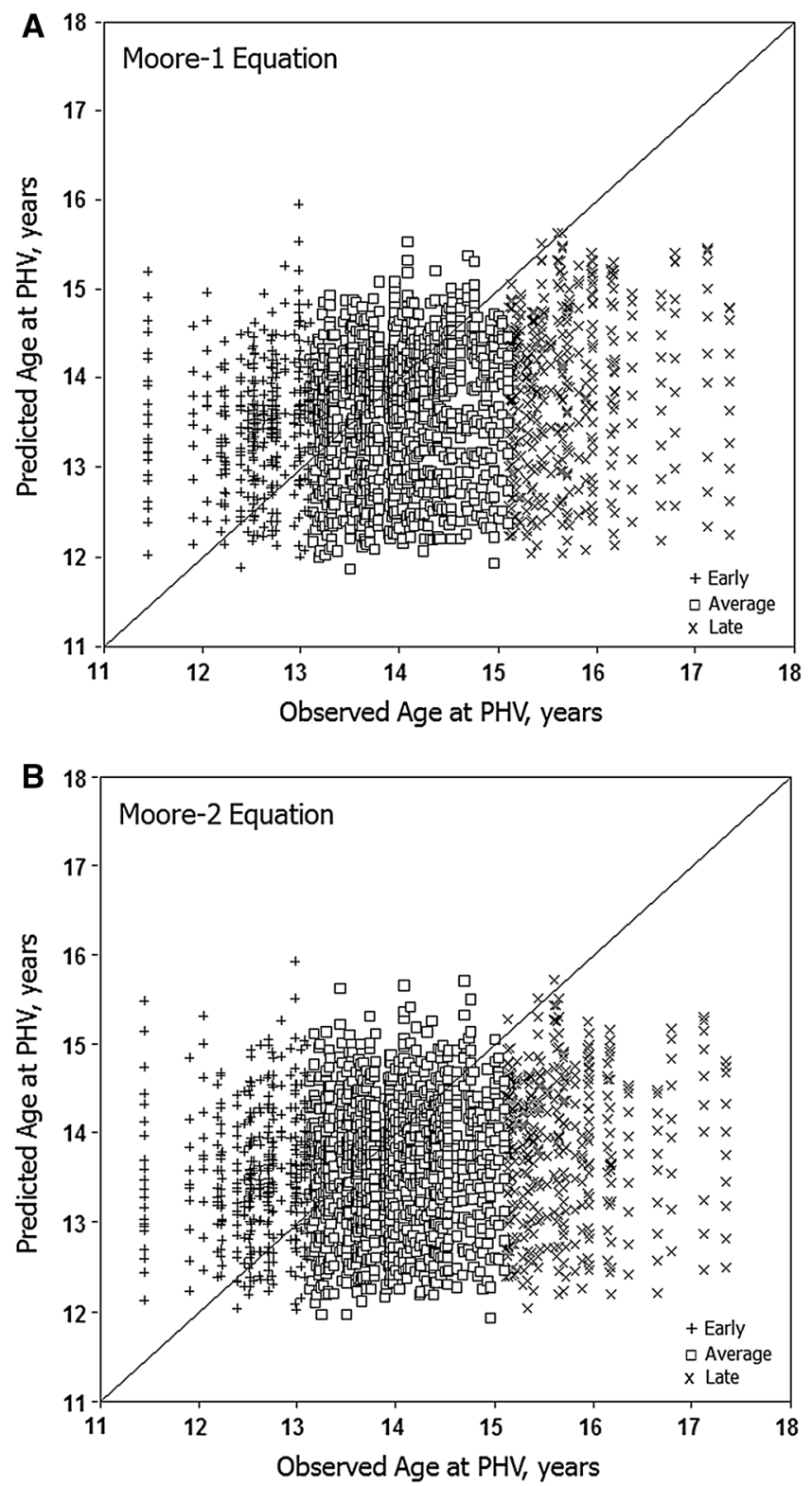

Fig. 3 Predicted ages at peak height velocity (PHV) in boys with the Moore-1 (a), Moore-2 (b) and Mirwald (c) equations plotted relative to observed age at PHV at each age for individual early, average and late maturing boys. Each vertical array shows predicted ages at PHV

were skeletally mature, and the number of mature athletes increased with CA [19]. These trends have implications for classifications based on predicted offset or age at PHV, especially at the maturity extremes.

Corresponding observations for female athletes are limited. Predicted age at PHV was used as an indicator of maturity status in a study of performance and motor coordination of gymnasts $6-8$ years of age [34]. Mean predicted ages at PHV increased from $6(11.2 \pm 0.2)$ to 8 $(11.6 \pm 0.2)$ years, but were considerably earlier and had reduced standard deviations compared with observed ages

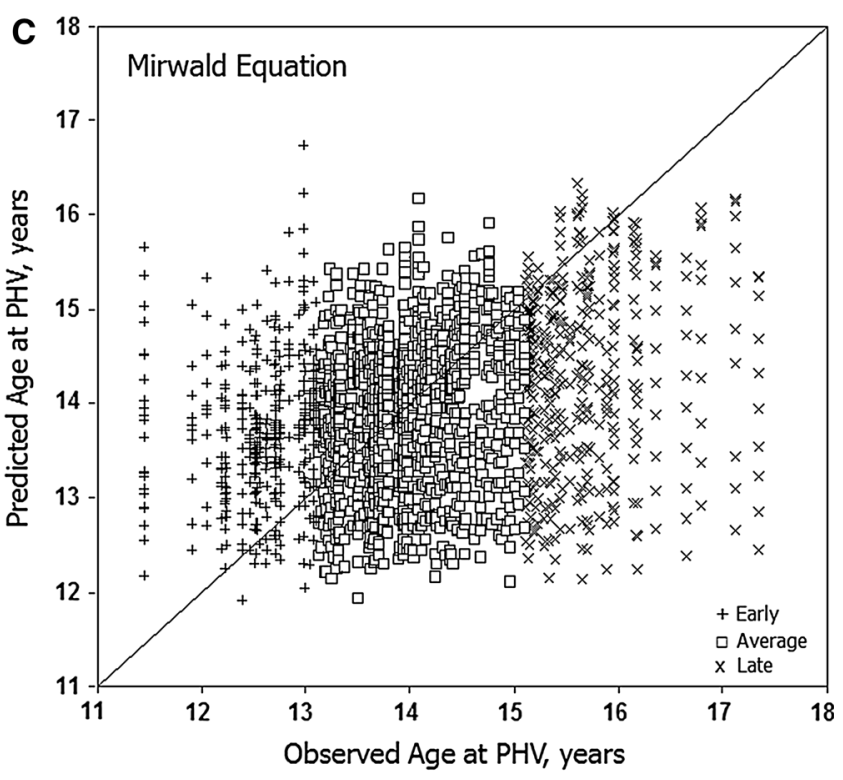

for an individual. The diagonal line indicates that predicted age at $\mathrm{PHV}$ is equivalent with observed age at PHV

at PHV in Belgian $(12.9 \pm 1.5$ years $)$ and Polish (13.2 \pm 0.9 years) gymnasts [35] and predicted age at PHV in a mixed-longitudinal sample of English gymnasts, $13.1 \pm 0.7$ years [36]. The latter estimate was likely influenced by CA range of the sample (8-17 years of age). Limitations of the original prediction equations with the sample of Belgian gymnasts have been previously reported [37]. The relatively early predicted ages at PHV among gymnasts $6-8$ years old also contrasted skeletal maturity observations. Skeletal age and CA did not differ, on average, among gymnasts aged 5-10 years; with increasing 

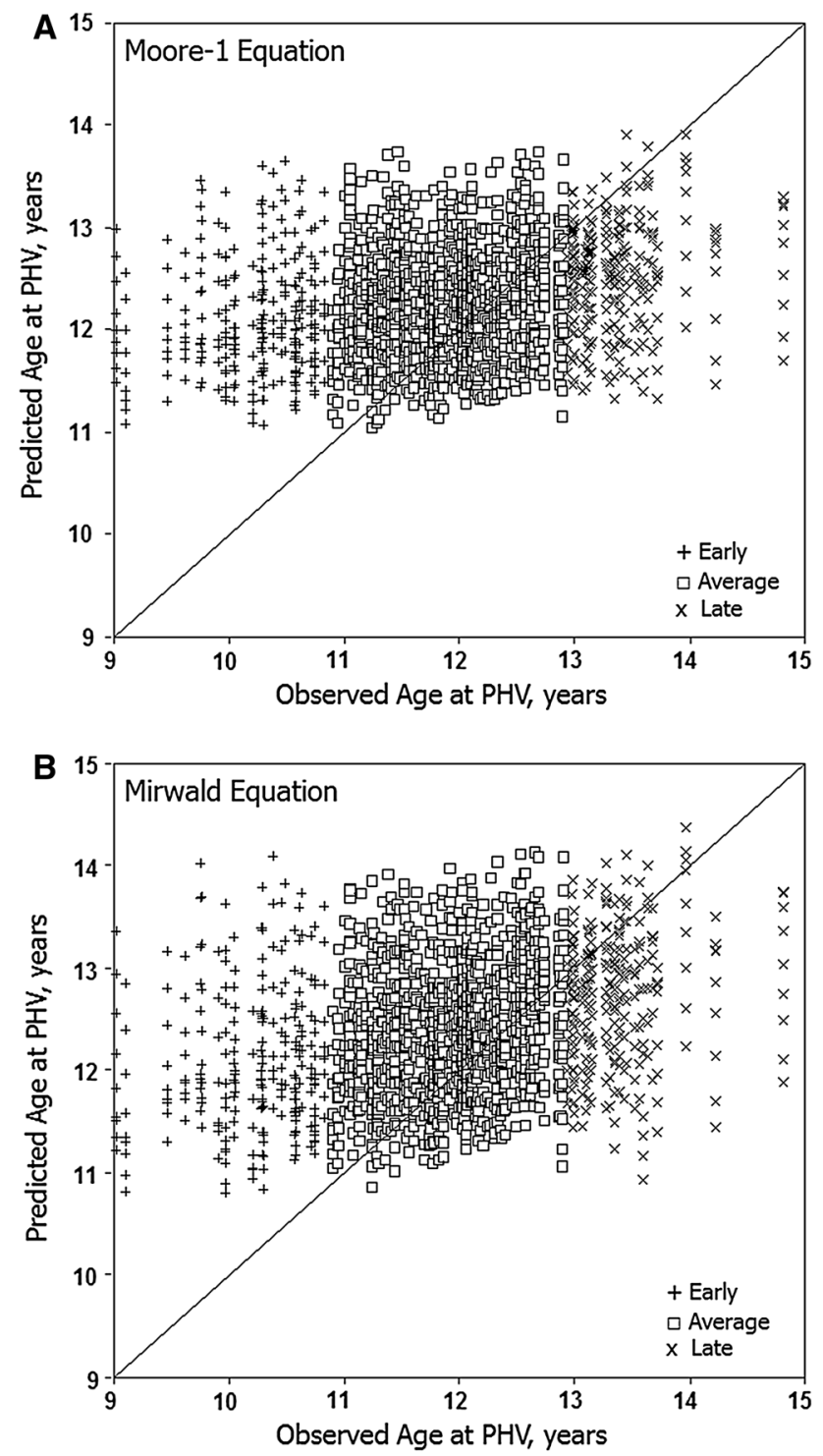

Fig. 4 Predicted ages at peak height velocity (PHV) with the Moore1 (a) and Mirwald (b) equations plotted relative to observed age at PHV at each age for individual early, average and late maturing girls. Each vertical array shows predicted ages at PHV for an individual. The diagonal line indicates that predicted age at PHV is equivalent with observed age at PHV

CA, SA lagged behind CA and the proportion of late maturing girls increased [19].

The adolescent growth spurt is often indicated as a risk factor for injury [38]. For example, the peak prevalence of Sever's disease (inflammation of the growth plate of the calcaneus) and Osgood-Schlatter's disease (inflammation of the patellar tendon of the anterior quadriceps muscle at the tibial tuberosity) occurred, respectively, in U-11 and U-13-U-14 academy soccer players, leading the authors to emphasise " ... the importance to football clubs of identifying the onset of these growth spurts to start early effective treatment and management and even prevention of these injuries" [39, p. 469-70]. The specific growth spurts were not identified. The two conditions accounted for $5 \%$ of all injuries among U-9-U-19 players; most Sever's ( $\sim 84 \%)$ and Osgood-Schlatter's $(\sim 87 \%)$ inflammations occurred among U-10-U-14 players and U-12-U-16 players, respectively. Both conditions are often attributed to rapid growth of the foot, lower leg (tibia) and thigh (femur), which occurs early in the male adolescent spurt [40].

Predicted age at PHV was related to injuries among 26 soccer players $(11.9 \pm 0.84$ years at initial selection) followed for 3 years [41]. The mean number of traumatic and overuse injuries per player were lower among pre-PHV players, but did not differ between players at PHV and post-PHV. A subsequent analysis suggested an increase in overuse injuries among players with an older age at PHV [42].

The growth and maturity status of injured athletes are not ordinarily reported. What specifically about the adolescent spurt renders a youngster at risk for injury? Is it the early acceleration of growth rate at take-off of the spurt or the peak velocity of growth at PHV? Is it the early rapid growth of the lower extremities? The differential timing of growth spurts in body segments (foot and leg length, sitting height), bone area and bone mineral, muscle mass and muscular strength and power [40] needs attention. Other factors including behavioural changes during adolescence and training environments per se [43] merit more detailed consideration in the context of injury risk.

Applications of maturity offset/predicted age at PHV are largely limited to the original equations [3]. Both have been used to classify youth into maturity groups and as a covariate or predictor in studies of athletes and non-athletes spanning late childhood through adolescence [1]. Dependence of offset on CA at prediction is problematic; e.g. correlations between CA and maturity offset were high in girls 11-16 years of age, 0.89 [44] and boys 8-18 years of age, 0.97 [45]. Among male soccer players 11-15 years of age, predicted offset with the new and original equations was highly correlated with CA (0.96, Moore-1; 0.96, Moore-2; 0.92, Mirwald) and with height (0.95, Moore-2; 0.94 , Mirwald) and sitting height (0.93, Moore-1) (unpublished, based on data in [32]).

Published applications of the new prediction equations [13] are limited. Maturity offset (using CA and height) was described in small samples of U-13 and U-15 soccer players participating in different training programmes, but was not considered in the analyses [14-16]. Predicted ages at PHV (using CA and height) did not differ between ranked and unranked elite U-14, U-15 and U16 tennis players of both sexes, but were a significant predictor of power in male though not in female athletes [17]. 
Age at PHV is a heritable characteristic as evident in several longitudinal studies of monozygotic (MZ) and dizygotic (DZ) twins [46-50]. Allowing for variation in methods of estimation, heritabilities for age at PHV were relatively high, 0.64-0.93, and implied a significant role for genotype. Heritabilities are sample statistics and may not apply to individuals. Nevertheless, intra-individual variability in predicted ages at PHV (Figs. 3, 4), and variation in predicted ages at PHV with CA per se (Tables 1,2) and maturity status (Figs. 1, 2) should be considered in this context.

Genetic tallness or shortness may also bias predictions. Heritabilities for stature are relatively high in samples of well-nourished twins, 0.69-0.96, and are similar for segment lengths [51]. Given two youngsters of the same CA, predicted offset and in turn age at PHV will likely differ between genetically tall and short individuals.

The new equations were simplified by reducing potential collinearity given the highly correlated predictors in the original equations (see Sect. 2). However, the standard errors were not appreciably reduced, $0.569-0.528$ year in girls, and $0.592-0.514$ (Moore-1) and 0.542 (Moore-2) in boys [3, 13].

The present study was not without limitations. Although conditions in Poland during the Wrocław study (1961-72) were not on par with Western countries, mean statures of boys [52] were comparable with contemporary Belgian and Canadian (Ontario) boys, but slightly shorter than UK boys [53] and Canadian (Saskatchewan) [54] boys. Mean statures of Wrocław girls [55] were shorter than Belgian, Canadian (Ontario, Saskatchewan) and UK girls [53, 54]. Sitting height/stature ratios of Wrocław boys and girls, however, overlapped with those for several European samples [53], while leg length/sitting height ratios overlapped with those of Canadian youth in the PBMAS (Table 5 in the ESM).

Secular variation is a related consideration. Heights of European youth increased over time after World War II, but have since slowed or stopped in many countries [56-60]. Median heights of US youth have not changed appreciably since the 1960s [60, 61]. However, secular increases in height were not necessarily associated with accelerated maturation between 1960 and 1980 in Belgium [56, 62] and between 1980 and 1997 in the Netherlands [63].

Mean ages at PHV of Wrocław boys (14.1 \pm 1.1 years) and girls (11.9 \pm 1.0 years) based on the Preece-Baines 1 model (this study) were similar to graphic estimates for Wrocław twins followed in 1967-83: boys-MZ $14.0 \pm 0.9$ years, $\quad$ DZ $14.0 \pm 1.0$ years; girls-MZ $11.8 \pm 1.0$ years, DZ $11.8 \pm 1.1$ years [64]. The PreeceBaines 1 model estimates for the male twins were similar, MZ $14.2 \pm 0.7$ years and DZ $14.1 \pm 0.9$ years [48]. Ages at PHV of Warsaw boys and girls followed in 1974-82 were $13.8 \pm 1.3$ and $11.8 \pm 0.7$ years, respectively [65], and of Poznań boys and girls followed in 1985-98 were $13.9 \pm 0.8$ and $11.8 \pm 0.9$ years, respectively [66]. Ages at menarche were also generally similar in the Polish samples, Wrocław Growth Study, $13.2 \pm 1.0$ years [11], Wrocław twins, MZ $13.1 \pm 1.0$ years, DZ $13.1 \pm 1.1$ years [67], Warsaw, $12.9 \pm 0.8$ years [65] and Poznań, $12.9 \pm 0.9$ years [66].

Mean ages at PHV in the Polish studies were similar to means in other European longitudinal studies, including Belgian boys (14.2 \pm 0.8 years) and girls (12.4 \pm 0.8 years), and UK boys (14.0 \pm 1.0 years) and girls (12.1 \pm 1.0 years $)$ used, respectively, in developing the original [3] and calibrating the new [13] prediction equations. Mean ages at PHV in European and North American longitudinal studies spanning the 1960s through 1990s varied between 13.3 and 14.4 years in boys and 11.3 and 12.2 years in girls [18, 40], and evidence for secular change over the past two generations was inconsistent [68]. Ages at PHV in Danish youth born in the 1930 s through 1960 s declined, from 12.5 to 12.0 years in girls and from 14.5 to 14.2 years in boys [69], while ages at PHV among American boys and girls born in the 1960s through 1980s did not differ [12].

Most information on secular change in maturity timing is based on age at menarche. Mean ages declined in European girls after World War II, but the declines were largely associated with reductions in the 90th percentiles rather than medians and 10th percentiles [57]. Evidence for recent secular change in menarche and pubertal onset and progress in USA was inconclusive [70-72].

Samples comprising longitudinal studies may or may not be representative of the population in general. Methods for estimating ages at PHV also vary [73]. No one method is the standard; all have underlying assumptions and limitations. Ages at PHV in Wrocław youth were estimated with the Preece-Baines Model 1; standard errors of the model fit compared favourably with other studies $[66,74]$. Ages at PHV in samples used to develop the new prediction equations were estimated with interpolating cubic splines in youth with "sufficient height measurements" (boys: 5 between 11.5 and 16.5 years; girls: 4 between 11.0 and 13.0 years). Running velocities were calculated; an interpolating cubic spline was fit "... in a regular grid to identify maximum height velocity

..." (and) based on visual selection, "... those that had clear peaks during the pubertal spurt as well as data pre-and postAPHV ..." were selected [13, p. 1757].

\section{Conclusion}

The present study validated the new maturity offset prediction equations [13] in 193 boys and 198 girls from the Wrocław Growth Study. Comparisons with the original equations [3] were also included. The new equations were 
useful for average maturing boys close to the time of PHV; a window for average maturing girls was not apparent. The new and original equations were not useful for early and late maturing boys and girls. Predicted offset and ages at PHV also had reduced ranges of variation compared with observed ages at PHV, more so with the new than the original equations.

Studies applying predicted offset and/or age at PHV are increasing as researchers attempt to address inter-individual differences in biological maturation. Attention to the details of maturity status and timing and to intra- and interindividual variability in status and timing is essential. Care in use of the equations and awareness of their limitations are also essential. Further validation and the development, refinement and evaluation of alternative approaches to maturity assessment are needed.

Acknowledgements The authors acknowledge the significant contributions of Prof. Tadeusz Bielicki who designed and carried out the Wrocław Growth Study and also of Prof. Jan Koniarek. The authors also thank Profs. Sean P. Cumming and Manuel J. Coelho-e-Silva for their critical reading of the revised manuscript.

\section{Compliance with Ethical Standards}

Funding No funding was received for the preparation of this article.

Conflict of interest Sławomir M. Kozieł and Robert M. Malina have no conflicts of interest directly relevant to the content of this article.

Open Access This article is distributed under the terms of the Creative Commons Attribution 4.0 International License (http:// creativecommons.org/licenses/by/4.0/), which permits unrestricted use, distribution, and reproduction in any medium, provided you give appropriate credit to the original author(s) and the source, provide a link to the Creative Commons license, and indicate if changes were made.

\section{References}

1. Malina RM. Top 10 research questions related to growth and maturation of relevance to physical activity, performance, and fitness. Res Q Exerc Sport. 2014;85:157-73.

2. Malina RM. Assessment of biological maturation. In: Armstrong $\mathrm{N}$, van Mechelen W, editors. Oxford textbook of children's exercise science and medicine. Oxford: Oxford University Press; 2017. p. 3-11.

3. Mirwald RL, Baxter-Jones ADG, Bailey DA, et al. An assessment of maturity from anthropometric measurements. Med Sci Sports Exerc. 2002;34:689-94.

4. Balyi I, Hamilton A. Long-term athlete development: trainability in childhood and adolescence: windows of opportunity, optimal trainability. Victoria: National Coaching Institute British Columbia and Advanced Training and Performance Ltd; 2004.

5. Balyi I, Cardinal C, Higgs C, et al. Canadian sport for life: longterm athlete development resource paper V2. Vancouver: Canadian Sport Centres; 2005. http://www.canadiansportforlife.ca/ default.aspx?PageID=1076\&LangID=en. Accessed 31 May 2017.
6. Meylan C, Cronin J, Oliver J, et al. Talent identification in soccer: the role of maturity status on physiological and technical characteristics. Int J Sport Sci Coach. 2010;5:571-92.

7. Lloyd RS, Oliver JL, Faigenbaum AD, et al. Chronological age vs. biological maturation: implications for exercise programming in youth. J Strength Cond Res. 2014;28:1454-64.

8. Granacher U, Lesinski M, Büsch D, et al. Effects of resistance training in youth athletes on muscular fitness and athletic performance: a conceptual model for long-term athlete development. Front Physiol. 2016;7(article 164):1-14.

9. Cumming SP, Lloyd RS, Oliver JL, et al. Biobanding in sport: Applications to competition, talent identification, and strength and conditioning of youth athletes. Strength Cond J. 2017;39:34-47.

10. Malina RM, Kozieł SM. Validation of maturity offset in a longitudinal sample of Polish boys. J Sports Sci. 2014;32:424-37.

11. Malina RM, Kozieł SM. Validation of maturity offset in a longitudinal sample of Polish girls. J Sports Sci. 2014;32:1374-82.

12. Malina RM, Choh AC, Czerwinski SA, et al. Validation of maturity offset in the Fels Longitudinal Study. Pediatr Exerc Sci. 2016;28:439-55.

13. Moore SA, McKay HA, Macdonald H, et al. Enhancing a somatic maturity prediction model. Med Sci Sports Exerc. 2015;47:1755-64.

14. Franco-Márquez F, Rodríguez-Rosell D, González-Suárez JM, et al. Effects of combined resistance training and plyometrics on physical performance in young soccer players. Int J Sports Med. 2015;36:906-14.

15. Rodríguez-Rosell D, Franco-Márquez F, Pareja-Blanco F, et al. Effects of 6 weeks resistance training combined with plyometric and speed exercises on physical performance of pre-peak height velocity soccer players. Int J Sports Physiol Perform. 2016;11:240-6.

16. Hammami R, Granacher U, Makhlouf I, et al. Sequencing effects of balance and plyometric training on physical performance in youth soccer athletes. J Strength Cond Res. 2016;30:3278-89.

17. Kramer T, Huijgen BCH, Elferink-Gemser MT, et al. A longitudinal study of physical fitness in elite junior tennis players. Ped Exerc Sci. 2016;28:553-64.

18. Malina RM, Beunen G. Monitoring growth and maturation. In: Bar-Or O, editor. The child and adolescent athlete. Oxford: Blackwell Science; 1996. p. 647-72.

19. Malina RM. Skeletal age and age verification in youth sport. Sports Med. 2011;41:925-47.

20. Bland JM, Altman DG. Statistical methods for assessing agreement between two methods of clinical measurement. Lancet. 1986;1(8476):307-10.

21. StatSoft, Inc. Statistica (data analysis software system), Version 12, 2014. http://www.statsoft.com. Accessed 31 May 2017.

22. Hauspie R, Bielicki T, Koniarek J. Skeletal maturity at onset of the adolescent growth spurt and at peak velocity for growth in height: a threshold effect. Ann Hum Biol. 1991;18:23-9.

23. Kozieł S. Factors affecting shape of growth curve during adolescence in boys and girls: doctoral dissertation. Wrocław: University of Wrocław; 1998.

24. Largo RH, Prader A. Pubertal development in Swiss boys. Helvet Paediatr Acta. 1983;38:211-28.

25. Largo RH, Prader A. Pubertal development in Swiss girls. Helvet Paediatr Acta. 1983;38:229-43.

26. Gil SM, Badiola A, Bidaurrazaga-Leton I, et al. Relationship between the relative age effect and anthropometry, maturity and performance in young soccer players. $J$ Sports Sci. 2014;32:475-86.

27. Mendez-Villanueva A, Buchheit M, Kuitunen S, et al. Is the relationship between sprinting and maximal aerobic speeds in 
young soccer players affected by maturation? Pediatr Exerc Sci. 2010;22:497-510.

28. Hammami R, Chaouachi A, Makhlouf I, et al. Associations between balance and muscle strength, power performance in male youth athletes of different maturity status. Pediatr Exerc Sci. 2016;28:524-34.

29. Meylan CM, Cronin J, Hopkins WG, et al. Adjustment of measures of strength and power in youth male athletes differing in body mass and maturation. Pediatr Exerc Sci. 2014;26:41-8.

30. Meyers RW, Oliver JL, Hughes MG, et al. Maximal sprint speed in boys of increasing maturity. Pediatr Exerc Sci. 2015;27:85-94.

31. Malina RM, Rogol AD, Cumming SP, et al. Biological maturation of youth athletes: assessment and implications. Br J Sports Med. 2015;49:852-9.

32. Malina RM, Coelho-e-Silva MJ, Figueiredo AJ, et al. Interrelationships among invasive and non-invasive indicators of biological maturation in adolescent male soccer players. J Sports Sci. 2012;30:1705-17.

33. Millar K. Patrick Thistle launch Scottish football's first 'bio-banding experiment'. The Scottish Sun, 14 April 2016, updated 26 October 2016. http://www.thescottishsun.co.uk/archives/news/154847/partickthistle-launch-scottish-footballs-first-bio-banding-experiment/. Accessed 2 Apr 2017.

34. Vandorpe B, Vandendriessche J, Vaeyens R, et al. Factors discriminating gymnasts by competitive level. Int J Sports Med. 2011;32:591-7.

35. Malina RM, Baxter-Jones ADG, Armstrong N, et al. Role of intensive training in the growth and maturation of artistic gymnastics. Sports Med. 2013;43:783-802.

36. Nurmi-Lawton JA, Baxter-Jones ADG, Mirwald RL, et al. Evidence of sustained skeletal benefits from impact-loading exercise in young females: a 3-year longitudinal study. J Bone Miner Res. 2004;19:314-22.

37. Malina RM, Claessens AL, Van Aken K, et al. Maturity offset in gymnasts: application of a prediction equation. Med Sci Sports Exerc. 2006;38:1342-7.

38. Malina RM. Injuries in organized sports for children and adolescents. In: Frost JL, editor. Children and injuries. Tucson: Lawyers and Judges Publishing Company; 2001. p. 199-248.

39. Price RJ, Hawkins RD, Hulse MA, et al. The Football Association medical research programme: an audit of injuries in academy youth football. Br J Sports Med. 2004;38:466-71.

40. Malina RM, Bouchard C, Bar-Or O. Growth, maturation, and physical activity. 2nd ed. Champaign: Human Kinetics; 2004.

41. van der Sluis A, Elferink-Gemser MT, Coelho-e-Silva MJ, et al. Sport injuries aligned to peak height velocity in talented pubertal soccer players. Int J Sports Med. 2014;35:351-5.

42. van der Sluis A, Elferink-Gemser MT, Brink MS, et al. Important of peak height velocity timing in terms of injuries in talented soccer players. Int J Sports Med. 2015;36:327-32.

43. Malina RM, Cumming SP, Coelho-e-Silva MJ, et al. Talent identification and development in the context of "growing up". In: Baker J, Cobley S, Schorer J, Wattie N, editors. Routledge handbook of talent identification and development in sports. New York: Routledge; 2017. p. 150-67.

44. Gay JL, Monsma EV, Torres-McGehee TM. Developmental and contextual risks of social physique anxiety among female athletes. Res Q Exerc Sport. 2011;82:168-77.

45. Machado D, Oikawa S, Barbanti V. The multicomponent anthropometric model for assessing body composition in a male pediatric population: a simultaneous prediction of fat mass, bone mineral content, and lean soft tissue. J Obes. 2013;2013:428135.

46. Fischbein S. Onset of puberty in MZ and DZ twins. Acta Genet Med Gemellol. 1977;26:151-7.
47. Bergmann P. The problem of genetic determination of growth at adolescence. Materiały i Prace Antropologiczne. 1988;108:165-216 (in Polish).

48. Hauspie R, Bergman P, Bielicki T, et al. Genetic variance in the pattern of the growth curve for height: a longitudinal analysis of male twins. Ann Hum Biol. 1994;21:347-62.

49. Beunen G, Thomis M, Maes $\mathrm{HH}$, et al. Genetic variance of adolescent growth in stature. Ann Hum Biol. 2000;27:173-86.

50. Silventoinen K, Haukka J, Dunkel L, et al. Genetics of pubertal timing and its associations with relative weight in childhood and adult height: the Swedish Young Male Twins Study. Pediatrics. 2008;121:e885-91.

51. Beunen GP, Peeters MW, Malina RM. Twin studies in sport performance. In: Bouchard C, Hoffman EP, editors. Genetic and molecular aspects of sport performance. West Sussex: Blackwell Publishing; 2011. p. 101-9.

52. Waliszko A, Jedlińska W. Wroclaw growth study. Part II: males. Stud Phys Anthropol. 1976;3:27-48.

53. Eveleth PB, Tanner JM. Worldwide variation in human growth. Cambridge: Cambridge University Press; 1976.

54. Mirwald DL, Bailey DA. Maximal aerobic power. London: Sports Dynamics; 1986.

55. Bielicki T, Waliszko A. Wrocław growth study. Part I: females. Stud Phys Anthropol. 1975;2:53-83.

56. Hauspie RC, Vercauteren M, Susanne C. Secular changes in growth and maturation: an update. Acta Paediatr Suppl. 1997;423:20-7.

57. Bodzsar EB, Susanne C. Secular growth changes in Europe: do we observe similar trends? Considerations for future research. In: Bodzsar EB, Susanne C, editors. Secular growth changes in Europe. Budapest: Eötvös University Press; 1998. p. 369-81.

58. Ong KK, Ahmed ML, Dunger DB. Lessons from large population studies on timing and tempo of puberty (secular trends and relation to body size): the European trend. Mol Cell Endocrinol. 2006;254-255:8-12.

59. Gohlke B, Woelfle J. Growth and puberty in German children: is there still a secular trend? Dtsch Arztebl Int. 2009;106:377-82.

60. Ogden CL, Fryar CD, Carroll MD, et al. Mean body weight, height, and body mass index, United States 1962-2002. Advance data from vital and health statistics, vol. 347. Hyattsville: National Center for Health Statistics; 2004.

61. McDowell MA, Fryar CD, Ogden CL, et al. Anthropometric reference data for children and adults: United States, 2003-2006. National health statistics reports, vol. 10. Hyattsville: National Center for Health Statistics; 2008.

62. Wellens R, Malina RM, Beunen G, et al. Age at menarche in Flemish girls: current status and secular change in the 20th century. Ann Hum Biol. 1990;17:145-52.

63. Mul D, Fredriks AM, van Buuren S, et al. Pubertal development in The Netherlands 1965-1997. Pediatr Res. 2001;50:479-86.

64. Bergman P, Goracy M. Comparative characterization of the course of growth and rate of growth in selected body dimensions in Wrocław twins age ( 8 to 18 years). Materiały i Prace Antropologiczne. 1988;108:119-63 (in Polish).

65. Malina RM, Woynarowska B, Bielicki T, et al. Prospective and retrospective longitudinal studies of the growth, maturation and fitness of Polish youth active in sport. Int $\mathrm{J}$ Sports Med. 1997;18(Suppl. 3):S179-85.

66. Kaczmarek M. Poznań longitudinal study: physical development of boys and girls. Monograph of the Institute of Anthropology, vol. 20. Poznań: Adam Mickiewicz University; 2001 (in Polish).

67. Bergman P, Orczykowska-Swiątkowska Z. Age at menarche in Wrocław twins. Materiały i Prace Antropologiczne. 1988;108:263-72 (in Polish). 
68. Roche AF, Sun S. Human growth: assessment and interpretation. Cambridge: Cambridge University Press; 2003. p. 172-87.

69. Aksglaede L, Olsen LW, Sørensen TIA, et al. Forty years trends in timing of pubertal growth spurt in 157,000 Danish school children. PLoS One. 2008;3(7):e2728.

70. Euling SY, Herman-Giddens ME, Lee PA, et al. Examination of US puberty-timing data from 1940 to 1994 for secular trends: panel findings. Pediatrics. 2008;121:S172-91.
71. Sun SS, Schubert CM, Liang R, et al. Is sexual maturity occurring earlier among U.S. children? J Adolesc Health. 2005;37:345-55.

72. Walvoord EC. The timing of puberty: is it changing? Does it matter? J Adolesc Health. 2010;47:433-9.

73. Hauspie RC, Cameron N, Molinari L, editors. Methods in human growth research. Cambridge: Cambridge University Press; 2004.

74. Kozieł S, Hauspie RC, Susanne C. Sex differences in height and sitting height in Belgian population. Int $\mathrm{J}$ Anthropol. 1995;10:187-95. 